\title{
Chronic Xanthogranulomatous Inflammatory Process and Calcinosis as a presenting feature of Childhood's Sjögren Syndrome
}

Igor De Melo Castro (UNIFACISA, Campina Grande, PB, Brasil), Sávio Nixon Passos Luz (UNIFACISA, Campina Grande, PB, Brasil), Yasmin Guimarães Araújo (UNIFACISA, Campina Grande, PB, Brasil), Yanne Pessoa Cavalcante (UNIFACISA, Campina Grande, PB, Brasil), Barbara De Araújo Batista (UNIFACISA, Campina Grande, PB, Brasil)

\section{BACKGROUND}

Sjögren Syndrome (SS) is a chronic autoimmune disease with the involvement of exocrine glands, affecting mainly lacrimal and salivary ones but with potential to have systemic disorders as well. This syndrome is classified as primary, or may be secondary to other autoimmune disorders, such as rheumatoid arthritis, systemic lupus erythematosus and others. Childhood SS is a rare condition and these cases may be underdiagnosed due to lack of typical symptoms at presentation. The standard criteria to diagnose adult SS may not be adequate for paediatric use. Despite a child-specific criteria have been proposed in order to minimize the number of underdiagnosed cases, there are still difficulties to establish the diagnosis in children.

\section{CASE REPORT}

A 9-year-old boy was referred to the rheumatology service presenting nodules in elbow extention surfaces, characteristically mobile and painless to palpation. The boy came to the first consult on January 2019 with an elbow nodule biopsy did on April 2017 that revealed chronic xanthogranulomatous inflammatory process with dystrophic calcification. At the physical exam, his muscular strength was preserved, and it was not flunlish arthritis. During the diagnostic investigation, a sonographic evaluation of the salivary glands was performed, demonstrating volumetric increase and textural modifications in parotid and submandibular glands, suggestive of an inflammatory process with associated adjacent lymph nodes. Ocular involvement has not been documented (Schirmer's test was negative). In addition, AntiRo/SSA, ANA and RF were positive; anti-centromere, anti-La/SSB, anti-CCP and ANCA were negative. The patient was diagnosed with possible childhood SS and medicated with Hydroxychloroquine $200 \mathrm{mg} / \mathrm{day}$.

\section{CONCLUSION}

In conclusion, Childhood SS is a rare condition difficult to diagnose due to the lack of symptoms presentation and its unspecific clinic, founds that contributes to the large number of underdiagnosed cases. Further studies are needed to define child-specific criteria and the association with chronic xanthogranulomatous inflammatory process and calcinosis. 